\title{
Microemulsions vs chitosan derivative-coated microemulsions for dermal delivery of 8-methoxypsoralen
}

This article was published in the following Dove Medical Press journal: International Journal of Nanomedicine

\author{
Jun-Yong $\mathrm{Wu}^{1-3, *}$ \\ Yong-Jiang $\mathrm{Li}^{\mathrm{I}-3, *}$ \\ Ting-Ting Liul-3 \\ $\mathrm{Ge} \mathrm{Ou}{ }^{1-3}$ \\ Xiong-Bin $\mathrm{Hu}^{1-3}$ \\ Tian-Tian Tang ${ }^{1-3}$ \\ Jie-Min Wang ${ }^{1-3}$ \\ Xin-Yi Liu ${ }^{1-3}$ \\ Da-Xiong Xiang ${ }^{1-3}$ \\ 'Department of Pharmacy, Second \\ Xiangya Hospital, Central South \\ University, Changsha, Hunan 4I00II, \\ People's Republic of China; ${ }^{2}$ Institute \\ of Clinical Pharmacy, Central South \\ University, Changsha, Hunan 4I00II, \\ People's Republic of China; ${ }^{3}$ Hunan \\ Provincial Engineering Research \\ Center of Translational Medicine and \\ Innovative Drugs, Changsha, Hunan, \\ People's Republic of China \\ *These authors contributed equally \\ to this work
}

Correspondence: Da-Xiong Xiang Department of Pharmacy, Second Xiangya Hospital, Central South University, 139 Middle Renmin Road, Changsha, Hunan 4I00II, People's Republic of China Email xiangdaxiong@csu.edu.cn
Background: 8-methoxypsoralen (8-MOP) is one of the most commonly utilized drugs in psoralen-ultraviolet A therapy for treatment of vitiligo. However, poor skin retention and systemic side effects limit the clinical application of 8-MOP.

Methods: Microemulsions (MEs) and chitosan derivative-coated 8-MOP MEs were developed and compared for dermal delivery of 8-MOP. Ex vivo skin retention/permeation study was performed to select the ME formulation with the highest retention:permeation ratio. Four different chitosan-coated MEs were prepared and compared with the ME formulation for their ability to distribute 8-MOP in the skin.

Results: Among various ME formulations developed, a formulation containing $2.9 \%$ ethyl oleate, $17.2 \%$ Cromophor EL35, 8.6\% ethanol and 71.3\% water showed the highest ex vivo skin retention:permeation ratio (1.98). Of four chitosan-coated MEs prepared, carboxymethyl chitosan-coated MEs (CC-MEs) and hydroxypropyl chitosan-coated MEs (HC-MEs) showed higher ex vivo skin retention:permeation ratio (1.46 and 1.84). and were selected for in vivo pharmacokinetic study. $\mathrm{AUC}_{\text {skin }}(0-12 \mathrm{~h})$ for 8-MOP MEs $\left(4578.56 \mathrm{~h} \cdot \mathrm{ng} \cdot \mathrm{mL}^{-1}\right)$ was higher than HC-MEs (3422.47 h.ng. $\left.\mathrm{mL}^{-1}\right)$, CC-MEs (2808.51 h.ng. $\left.\mathrm{mL}^{-1}\right)$ and tincture $\left(1500.16 \mathrm{~h} \cdot \mathrm{ng} \cdot \mathrm{mL}^{-1}\right)$. Also, $\mathrm{AUC}_{\text {plasma }}(0-12 \mathrm{~h})$ for MEs $\left(39.35 \pm 13.90 \mathrm{~h} \cdot \mathrm{ng} \cdot \mathrm{mL}^{-1}\right)$ was significantly lower than HC-MEs (66.32 h.ng. $\left.\mathrm{mL}^{-1}\right)$, CC-MEs $\left(59.70 \mathrm{~h} \cdot \mathrm{ng} \cdot \mathrm{mL}^{-1}\right)$ and tincture $\left(73.02 \mathrm{~h} \cdot \mathrm{ng} \cdot \mathrm{mL}^{-1}\right)$.

Conclusion: These combined results suggested that the MEs developed could be a promising and safe alternative for targeted skin delivery of 8-MOP.

Keywords: 8-methoxypsoralen, microemulsion, chitosan-coated microemulsion, ex vivo permeation, microdialysis, pharmacokinetics

\section{Background}

Vitiligo is a skin disease of spontaneous hypopigmentation characterized by white patches on different areas of the body. ${ }^{1,2}$ Vitiligo is caused by skin- and hair-follicle melanin depigmentation, but the pathogenesis remains unclear. ${ }^{3}$ About $1 \%-2 \%$ of people are affected by vitiligo globally, with no predilection for age, sex, or race. ${ }^{4}$ This disease is easy to diagnose, but few treatments are available, and patient quality of life is often been negatively affected. ${ }^{5}$

Photochemotherapy using psoralen or its derivatives plus ultraviolet $\mathrm{A}$ is an effective treatment for vitiligo, and has been approved by the US Food and Drug Administration and regulatory agencies in European countries. ${ }^{6}$ 8-Methoxypsoralen (8-MOP) is one of the most commonly utilized drugs in psoralen-ultraviolet A therapy. ${ }^{7,8}$ 8-MOP may activate tyrosinase in the horny layer of the skin, promoting melanin synthesis and facilitating the proliferation and migration of melanocytes. ${ }^{9} 8$-MOP 
may also stimulate keratinocytes to release inflammatory mediators that could enhance melanocyte function and serve as melanocyte growth-stimulating factors. ${ }^{10}$

Traditional topical 8-MOP formulations, such as solutions, ${ }^{11}$ creams, ${ }^{12}$ and tinctures,${ }^{13}$ are efficacious; however, significant systemic side effects, including pain, pruritus, vesicular erythema, severe phototoxic erythema, hepatic toxicity, and renal toxicity, limit its usage. ${ }^{14}$ Studies have shown that the target of 8-MOP therapeutic treatment of vitiligo is the epidermis. ${ }^{15,16}$ Therefore, enhanced skin targeting and reduced skin permeation of 8-MOP are warranted for improving therapeutic efficacy and avoiding its potential side effects. Also, high concentration of 8-MOP in the skin helps to reduce the dose of ultraviolet A radiation exposure and associated side effects. ${ }^{17}$

Microemulsions (MEs) are thermodynamically stable isotropic systems with small particles $(<100 \mathrm{~nm}) .{ }^{18}$ MEs can regulate the distribution of skin retention and transdermal absorption of encapsulated drug. Reports indicate that MEs can improve drug absorption in the skin, and they have been suggested as promising candidates for transdermal delivery. ${ }^{19-21}$ Chitosan-coated MEs, which have emerged as a novel carrier for transdermal delivery of chitosan and its derivatives, with high biocompatibility and low toxicity, may help to permeate the stratum corneum and open tight junctions in skin. ${ }^{22}$ The aim of this study was to enhance the retention of 8-MOP in the skin and reduce its entry to the bloodstream (skin permeation) using MEs and chitosan derivative-coated MEs as delivery vehicles.

\section{Methods}

\section{Materials}

8-MOP were purchased from Japharm (Nanjing, China). 8-MOP tincture ( $1 \mathrm{mg} \mathrm{mL}^{-1} 8$-MOP in ethanol-water) was purchased from Huapont Pharm (Chongqing, China). Isopropyl myristate, Cremophor EL35, and Cremophor RH40 were purchased from BASF (Ludwigshafen, Germany). Ethyl oleate, oleic acid, oleoyl macrogolglycerides (Labrafil M 1944 CS), and medium-chain triglycerides were obtained from Gattefossé (France). Polyoxyethylene stearate (Solutol) and polyethylene glycol $400\left(\mathrm{PEG}_{400}\right)$ were purchased from Sinopharm Chemical Reagent (Shanghai, China). Cabomer-940 was purchased from Shin-Etsu Chemical Japan. Lactate chitosan (LC), carboxymethyl chitosan (CC), acetic chitosan (AC), and hydroxypropyl chitosan (HC) were purchased from Sinopharm Chemical Reagent (Shanghai, China). 4,8,5'-Trimethylpsoralen (TMP) was purchased from Tauto Biotech (Shanghai, China). High-performance liquid chromatography (HPLC)-grade methanol and acetonitrile were obtained from Tedia (Fairfield, OH, USA). Doubledistilled water was used throughout the study. All other chemical reagents and solvents were of analytical grade.

\section{Preparation of 8-MOP MEs}

Ethanol and propylene glycol were chosen as cosurfactants for their good solubility of 8-MOP and mixed with Cremophor EL35, RH40, or Solutol at a weight ratio of 1:2 $\left(\mathrm{K}_{\mathrm{M}} 2: 1\right)$ to form mixtures $\left(\mathrm{S}_{\text {mix }}\right)$. Then, $\mathrm{S}_{\text {mix }}$ was added to ethyl oleate, oleic acid, Labrafil M 1944 CS, medium-chain triglycerides, or isopropyl myristate at weight ratios of 9:1, $8: 2,7: 3$, and 6:4, respectively. Double-distilled water was added dropwise to the oil and $\mathrm{S}_{\text {mix }}$ with magnetic stirring at ambient temperature. Therefore, a total of 120 different preparations were prepared and tested. After 2 weeks of storage at ambient temperature, ten drug-free preparations that successfully formulated MEs were included for drug loading. Then, the $\mathrm{K}_{\mathrm{M}}$ values of the included MEs with good stability were changed to $3,1.5$, and 1 . After 1 month of storage at ambient temperature, homogeneous, clear, and transparent formulations were chosen for preparation of MEs for loading 8-MOP. Drug-loaded MEs were prepared by adding $20 \mathrm{mg}$ 8-MOP into $20 \mathrm{~mL}$ MEs with stirring at $25^{\circ} \mathrm{C}$ for 2 hours, followed by centrifugation at $13,000 \mathrm{rpm}$ for 10 minutes. Supernatants were purified 8-MOP-loaded MEs and were stored in vials for 1 week at ambient temperature. Three formulations, which were homogeneous, clear, and transparent, were selected for further experiments.

\section{Ex vivo skin retention/permeation study of 8-MOP MEs}

The ex vivo skin-permeation study was carried out in accordance with the recommendations in the Guide for the Care and Use of Laboratory Animals and approved by the Animal Ethical Committee of the Second Xiangya Hospital of Central South University. The permeability of three drug-loaded MEs was determined using a modified Franz-type diffusion cell (Pharmacopoeia Standard Instrument, Tianjin, China) fitted with excised porcine skin obtained from the abdomen of a healthy pig $(10 \mathrm{~kg})$.

The skin was mounted on the receptor compartment with the stratum corneum facing up into the donor compartment and the dermal side facing down into the receptor compartment. The donor cell was filled with $1 \mathrm{~mL}$ drugloaded ME or 8-MOP tincture. The receptor compartment was filled with $17 \mathrm{~mL}$ physiological saline containing $30 \%$ $\mathrm{PEG}_{400} \mathrm{v}: \mathrm{v}$ as the receptor phase and maintained at $37^{\circ} \mathrm{C} \pm 1^{\circ} \mathrm{C}$, with constant stirring at $200 \mathrm{rpm}$. The effective diffusion area was $1.77 \mathrm{~cm}^{2}$. At predesignated time points $(1,2,4,6,8$, 
12, and 24 hours), $400 \mu \mathrm{L}$ receptor phase was removed and replaced with $400 \mu \mathrm{L}$ fresh phase. Permeation was calculated:

$$
\mathrm{Q}_{\mathrm{n}}=\left(\mathrm{C}_{\mathrm{n}} \mathrm{V}+\sum \mathrm{C}_{\mathrm{i}} \mathrm{V}_{\mathrm{i}}\right) / \mathrm{S}
$$

where $\mathrm{Q}_{\mathrm{n}}$ is the cumulative amount of 8-MOP at time $t$, $\mathrm{C}_{\mathrm{n}}$ the concentration of 8-MOP in the receptor phase at point $\mathrm{n}$, $\mathrm{C}_{\mathrm{i}}$ the concentration of 8-MOP in the receptor phase at point $\mathrm{i}$, $\mathrm{V}$ volume of the receptor phase, $\mathrm{V}_{\mathrm{i}}$ removed volume of the receptor phase at point $\mathrm{n}-1$, and $\mathrm{S}$ the effective diffusion area.

Following the ex vivo skin-permeation experiments, the amount of 8-MOP retained in the skin was determined by homogenization. After being washed three times with triple-distilled water, the skin was cut into small pieces and placed into a $5 \mathrm{~mL}$ volumetric flask containing $3 \mathrm{~mL}$ methanol. Sample extraction was performed by sonication for 30 minutes and diluting with methanol to an appropriate volume. The resulting solution was centrifuged at 13,000 rpm for 10 minutes. The supernatant was analyzed by HPLC, and 8-MOP retained in the skin calculated:

$$
\mathrm{Q}_{\text {skin }}=\mathrm{CV} / \mathrm{m}
$$

where, $\mathrm{Q}_{\text {skin }}$ is the amount of 8-MOP retained in the skin at time $\mathrm{t}, \mathrm{C}$ the concentration of 8-MOP in skin, $\mathrm{V}$ the volume of sample analyzed and $\mathrm{m}$ the weight of the skin samples.

The ME formulation with the highest retention:permeation ratio was selected for chitosan coating and in vivo evaluations.

\section{Characterization of selected 8-MOP MEs}

The ME formulation with the appropriate drug-loading capacity and highest drug retention:permeation ratio in ex vivo skin was subjected to physicochemical characterization.

\section{Appearance and micromorphology of selected 8-MOP MEs}

Visual inspection of 8-MOP ME appearance by transmission electron microscopy (TEM; JEM-1200EX; Jeol, Tokyo, Japan) was employed to visualize 8-MOP ME microstructure. 8-MOP MEs were placed in $4 \mathrm{~mL}$ Eppendorf tubes and diluted 20 -fold. The diluent was dropped on a copper mesh covered with carbon film, and filter paper was used to absorb the excess liquid. After the diluent had been dried in air, the carbon film was placed under TEM to observe 8-MOP ME morphology.

Determination of physiochemical characterization of selected 8-MOP MEs

Mean droplet size, polydispersity index (PDI), and $\zeta$-potential of the MEs were characterized using a laser particle-size analyzer (Nano ZS90; Malvern). An appropriate 8-MOP ME volume was transferred into a $10 \mathrm{~mL}$ Eppendorf tube and diluted 50 times for detection at $25^{\circ} \mathrm{C}$. $\mathrm{pH}$ values and electronic conductivity were evaluated with a DDS-11A digital conductivity meter (Leida, Shanghai, China).

\section{Preliminary stability of selected 8-MOP MEs}

The 8-MOP ME was stored at $25^{\circ} \mathrm{C}$ or $4^{\circ} \mathrm{C}$ for 60 months. Stability was evaluated by visual inspection, centrifugal stability, and physicochemical characterization on days 30 and 60 .

\section{Preparation of chitosan derivative-coated 8-MOP MEs}

At a concentration of $0.75 \%, \mathrm{LC}, \mathrm{CC}, \mathrm{AC}$, and $\mathrm{HC}$ were used to replace the water phase in the selected formulation of 8-MOP MEs to formulate LC-coated 8-MOP MEs, CC-coated 8-MOP MEs, AC-coated 8-MOP MEs, and HC-coated 8-MOP MEs.

\section{Characterization of chitosan derivative- coated 8-MOP MEs}

Characterization of chitosan derivative-coated 8-MOP MEs was conducted the same as for the selected 8-MOP MEs, including TEM, droplet size, PDI, $\zeta$-potential, $\mathrm{pH}$, electronic conductivity, and maximum drug-loading capacity. For drug loading-capacity calculation, $100 \mu \mathrm{L}$ MEs or chitosan derivative-coated MEs were diluted by adding methanol with sonication for 15 minutes, and the samples were analyzed by HPLC. Also, preliminary stability of selected chitosan derivative-coated 8-MOP MEs was evaluated.

\section{Comparison of ex vivo skin permeation of 8-MOP MEs and chitosan derivative- coated 8-MOP MEs}

Ex vivo skin-permeation experiments were conducted in the same fashion to compare skin retention and permeation of the 8-MOP in MEs and in chitosan derivative-coated ME formulations. Chitosan derivative-coated 8-MOP MEs with higher retention:permeation ratio were selected for in vivo microdialysis experiments.

\section{HPLC analysis of ex vivo skin-permeation study samples}

Receptor-phase samples were filtered through $0.22 \mu \mathrm{m}$ polytetrafluoroethylene filters (Millipore) and then analyzed with a validated HPLC method. Skin samples were prepared as described in the ex vivo skin-permeation study. Receptorphase samples and supernatant of skin samples were analyzed by HPLC using a Welchrom $\mathrm{C}_{18}$ column $(5 \mu \mathrm{m}, 4.6 \times 250 \mathrm{~nm})$ with a methanol:water ratio of 58:42 v:v as the mobile phase. 
Flow rate was fixed at $1 \mathrm{~mL} / \mathrm{min}$ and ultraviolet-detection wavelength at $\lambda=249 \mathrm{~nm}$.

\section{Microdialysis system}

To test the in vivo skin-targeting efficacy of 8-MOP MEs and chitosan derivative-coated 8-MOP MEs, a microdialysis system was developed. CMA 30 linear microdialysis probes with a $6 \mathrm{kDa}$ membrane cutoff and a dialysis membrane length of $10 \mathrm{~mm}$ were used (model 801,0460; CMA Microdialysis, Solna, Sweden). A microsyringe pump (CMA 102) was used to pump the perfusate at different constant flow rates, and microdialysate samples were collected in $0.6 \mathrm{~mL}$ amber polypropylene tubes (Thermo Fisher Scientific, Waltham, MA, USA) using a CMA 170 automated collector system.

\section{Pharmacokinetic study}

In vitro recovery

The pharmacokinetic study on animals was carried out in accordance with the recommendations in the Guide for the Care and Use of Laboratory Animals and approved by the Animal Ethical Committee of the Second Xiangya Hospital of Central South University. Both incremental and decremental methods were used to test in vitro microdialysis recovery. For the incremental method, the probe was sunk in three different concentrations of 8 -MOP $\left(5,50\right.$, and $\left.600 \mathrm{ng} \mathrm{mL}^{-1}\right)$ and isotonic PBS was perfused. For the decremental method, the probe was sunk in isotonic PBS and three different concentrations of 8-MOP (5, 50 , and $600 \mathrm{ng} \mathrm{mL}^{-1}$ ) were perfused. The perfusion flow rate was fixed at $1 \mu \mathrm{L} \mathrm{min}{ }^{-1}$. After an equilibration period of 1 hour, microdialysates $(60 \mu \mathrm{L})$ were collected every hour for 5 hours. Collected samples were analyzed using a validated HPLC method. Relative recovery was obtained by the incremental method and relative loss by the decremental method. ${ }^{23,24}$

\section{In vivo recovery}

Male Sprague Dawley rats $(n=5)$ were anesthetized with $1 \%$ pentobarbital sodium $(40 \mathrm{mg} / \mathrm{kg})$, and a temperaturemaintaining heating pad $\left(37^{\circ} \mathrm{C}\right)$ was used to control body temperature. Abdominal fur was shaved from the dorsal area $(3 \times 3 \times 0.2 \mathrm{~cm})$. A CMA 30 dermal probe was inserted through the tip of the cannula and the introducer needle then retracted, leaving the dialysis membrane implanted in the dermal tissue of the ventral region. Three concentrations of 8-MOP $\left(5,50\right.$, and $\left.600 \mathrm{ng} \mathrm{mL}^{-1}\right)$ solution were perfused. Perfusion, equilibration, and sample collection were performed as for in vitro recovery experiments.

\section{Stability of in vivo recovery}

For evaluation of stability of in vivo recovery, a moderate concentration of 8 -MOP $\left(50 \mathrm{ng} \mathrm{mL} \mathrm{mL}^{-1}\right)$ was used.
Microdialysis parameters were the same, but samples were collected every hour for 12 hours.

\section{Administration and microdialysis}

A total of 24 male Sprague Dawley rats weighing 200-250 g were used for in vivo microdialysis study. The animals were housed in well-spaced ventilated cages and maintained on healthy diets. Prior to the studies, the animals were fasted for 12 hours. Animals were separated into three groups. Anesthetization and fur shaving were as previously described. Group $1(\mathrm{n}=6)$ received $0.1 \%$ 8-MOP tincture $(0.7 \mathrm{~mL})$, group $2(\mathrm{n}=6)$ 8-MOP MEs, and group $3(n=6)$ and group $4(n=6)$ received two selected chitosan derivative-coated ME formulations each. All formulations were applied to medical gauze and overlaid on exposed skin $(3 \times 3 \times 0.22 \mathrm{~cm})$ at an equivalent 8 -MOP dose $(0.7 \mu \mathrm{g})$. Microdialysis conditions and sample collections were as previously described. Blood samples were collected from tail veins of rats at predetermined time intervals. After the last blood sampling, the hairless skin was excised and the formulation wiped off using medical alcohol. All procedures were carried out in accordance with the recommendations in the Guide for the Care and Use of Laboratory Animals. The protocol was approved by the ethics committee of the Second Xiangya Hospital of Central South University.

\section{UPLC-MS analysis of pharmacokinetic study samples}

For microdialysate samples, $60 \mu \mathrm{L}$ of each sample was collected in a $1.5 \mathrm{~mL}$ Eppendorf tube, mixing with $30 \mu \mathrm{L}$ TMP (200 ng $\mathrm{mL}^{-1}$ ) as internal standard. Then, ethyl acetate $(600 \mu \mathrm{L})$ was added, with vortexing for 5 minutes. Supernatant $(550 \mu \mathrm{L})$ was collected after centrifuging at $15,000 \mathrm{rpm}$ for 10 minutes $\left(10^{\circ} \mathrm{C}\right)$. After vacuum drying $\left(37^{\circ} \mathrm{C}\right)$, the residual was dissolved with methanol $(60 \mu \mathrm{L})$ and analyzed by ultraperformance LC (UPLC) mass spectrometry (MS). For blood samples, sera were obtained by centrifuging samples at 5,000 rpm for 10 minutes. Serum $(150 \mu \mathrm{L})$ was mixed with $30 \mu \mathrm{L}$ TMP $\left(200 \mathrm{ng} \mathrm{mL} \mathrm{mL}^{-1}\right)$. Then, ethyl acetate $(1,000 \mu \mathrm{L})$ was added, with vortexing for 5 minutes. Supernatant $(950 \mu \mathrm{L})$ was collected after centrifugation at $15,000 \mathrm{rpm}$ for 10 minutes $\left(10^{\circ} \mathrm{C}\right)$. After vacuum drying $\left(37^{\circ} \mathrm{C}\right)$, the residual was dissolved with methanol $(60 \mu \mathrm{L})$ and analyzed by UPLC-MS.

A UPLC-MS system equipped with an LC-20A workstation (Shimadzu, Kyoto, Japan) with quadrupole linear ion-trap MS (4,000 Q Trap; Applied Biosystems, Foster City, CA, USA). Chromatographic conditions were 
A

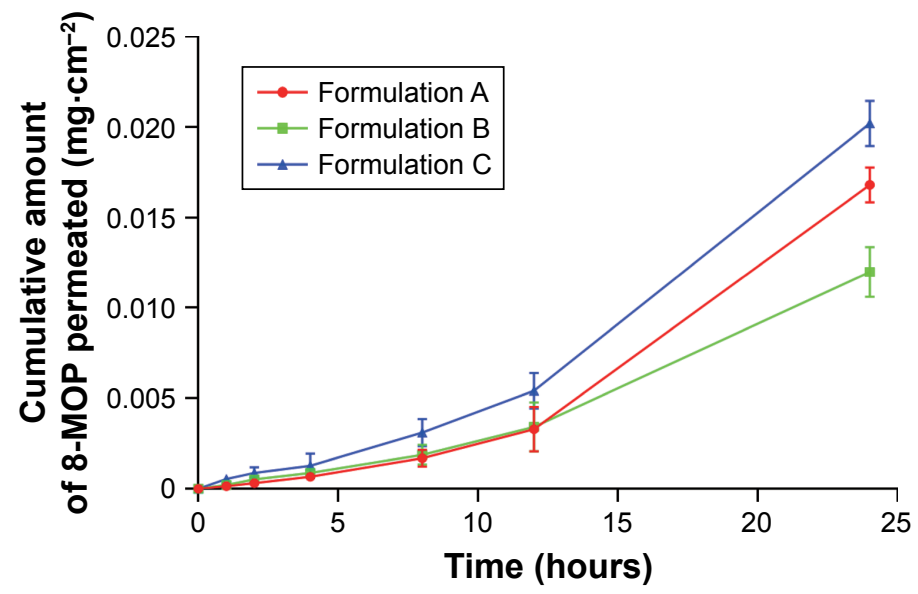

B

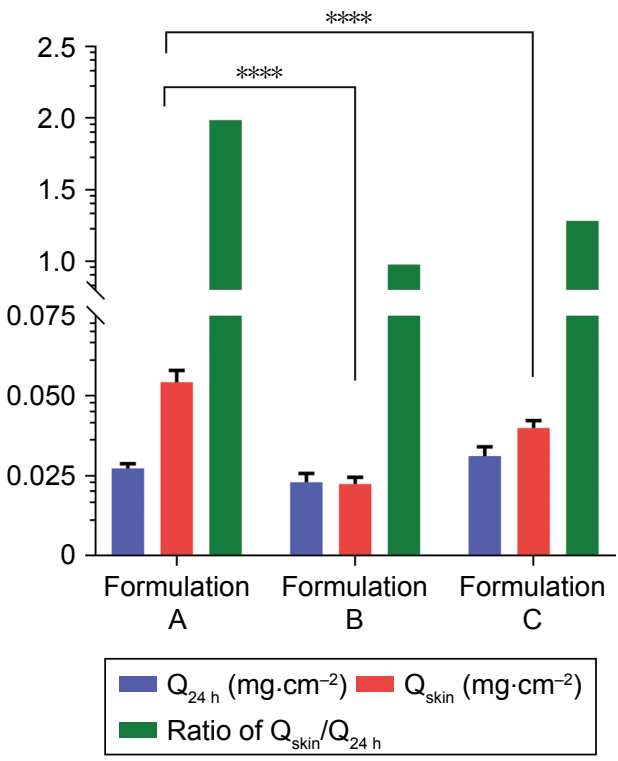

Figure I Ex vivo skin-permeation profile of the three ME formulations $(n=6)$.

Notes: (A) Cumulative 12-hour 8-MOP permeation; (B) comparison of amount of 8-MOP retained and permeated in the skin and calculated retention:permeation ratio $(* * * * P<0.000 \mathrm{I})$. Formulation $\mathrm{A}$ showed a significant higher amount of 8 -MOP retained in the skin than formulation $\mathrm{B}$ and $\mathrm{C}$, formulation $\mathrm{A}$ also showed the highest ratio of retention/permeation.

Abbreviations: ME, microemulsion; MOP, methoxypsoralen.

Xtimate XB-C8 column $(2.1 \times 30 \mathrm{~mm}, 3 \mu \mathrm{m}$, Welch material), methanol:water 70:30 v: $\mathrm{v}$ as mobile phase, fixed flow rate $0.25 \mathrm{~mL} \mathrm{~min}^{-1}$, and temperature $450^{\circ} \mathrm{C}$. MS conditions were electrospray-ionization probe operated in positiveionization mode, capillary voltage $3 \mathrm{kV}$, cone voltage $35 \mathrm{kV}$, extractor voltage $3 \mathrm{kV}$, multiple reaction-monitoring transitions at mass-to-charge ratios $(\mathrm{m} / \mathrm{z})$ of $229.1 \rightarrow 141.9$ for 8-MOP, and desolvation temperature $450^{\circ} \mathrm{C}$.

\section{Statistical analysis}

All statistical analyses were performed with SPSS 19.0. Results are expressed as mean \pm SD. The differences among groups were evaluated by ANOVA, followed by Duncan's multiple-range tests. All data analyses were performed at a significance level of $\alpha=0.05$.

\section{Results}

\section{Preparation of 8-MOP ME formulations}

Among various formulations tested, three (A, B, and C) exhibited good stability after 1 month of storage and were selected for ex vivo skin-permeation study. Details of composition are available in Table S1.

\section{Ex vivo skin retention/permeation study of 8-MOP ME formulations}

Results of ex vivo skin-permeation study for the three 8-MOP ME formulations are shown in Figure 1. Details of ex vivo skin-permeation profiles are summarized in Table 1. Briefly, the permeation rate and cumulative permeated amount of
8-MOP of formulation A were lower than formulation C, but higher than formulation B. However, formulation A showed the highest skin retention of 8-MOP, as well as highest retention:permeation ratio. Therefore, formulation A, with the highest retention:permeation ratio of 1.98 , was the optimal formulation of 8-MOP ME and was selected for further experiments.

\section{Characterization of selected 8-MOP MEs}

The selected 8-MOP MEs (formulation A) were colorless, transparent, and homogeneous, with slight pale-blue opalescence and good fluidity. 8-MOP ME particles were spherical and uniformly distributed in the system when observed under TEM (Figure 2A). The mean droplet size of 8-MOP ME was $17.303 \mathrm{~nm}$, with PDI $0.142, \zeta$-potential $-17.40 \mathrm{mV}, \mathrm{pH} 6.225$, and electronic conductivity $24.75 \mu \mathrm{S} \cdot \mathrm{cm}^{-1}$ (Table 2). The appearance, clarity, and physicochemical characterizations of samples had not changed after 60 days of storage at $4^{\circ} \mathrm{C}$ or $25^{\circ} \mathrm{C}$ (Table S2).

Table I Ex vivo skin-permeation profile of three 8-MOP ME formulations

\begin{tabular}{l|l|l|l}
\hline & $\mathbf{Q}_{24 \text { hours }}\left(\mathbf{m g} \cdot \mathbf{c m}^{-2}\right)$ & $\mathbf{Q}_{\text {skin }}\left(\mathbf{m g} \cdot \mathbf{c m}^{-2}\right)$ & $\begin{array}{l}\text { Retention: } \\
\text { permeation }\end{array}$ \\
\hline A & $0.02735 \pm 0.00146$ & $0.05431 \pm 0.00364$ & $1.98^{*}$ \\
B & $0.02304 \pm 0.00278$ & $0.02249 \pm 0.00210$ & 0.98 \\
C & $0.03120 \pm 0.00289$ & $0.03999 \pm 0.00228$ & 1.28 \\
\hline
\end{tabular}

Note: $* P<0.01$ versus formulation $B$ and formulation $C$.

Abbreviations: MOP, methoxypsoralen; ME, microemulsion. 

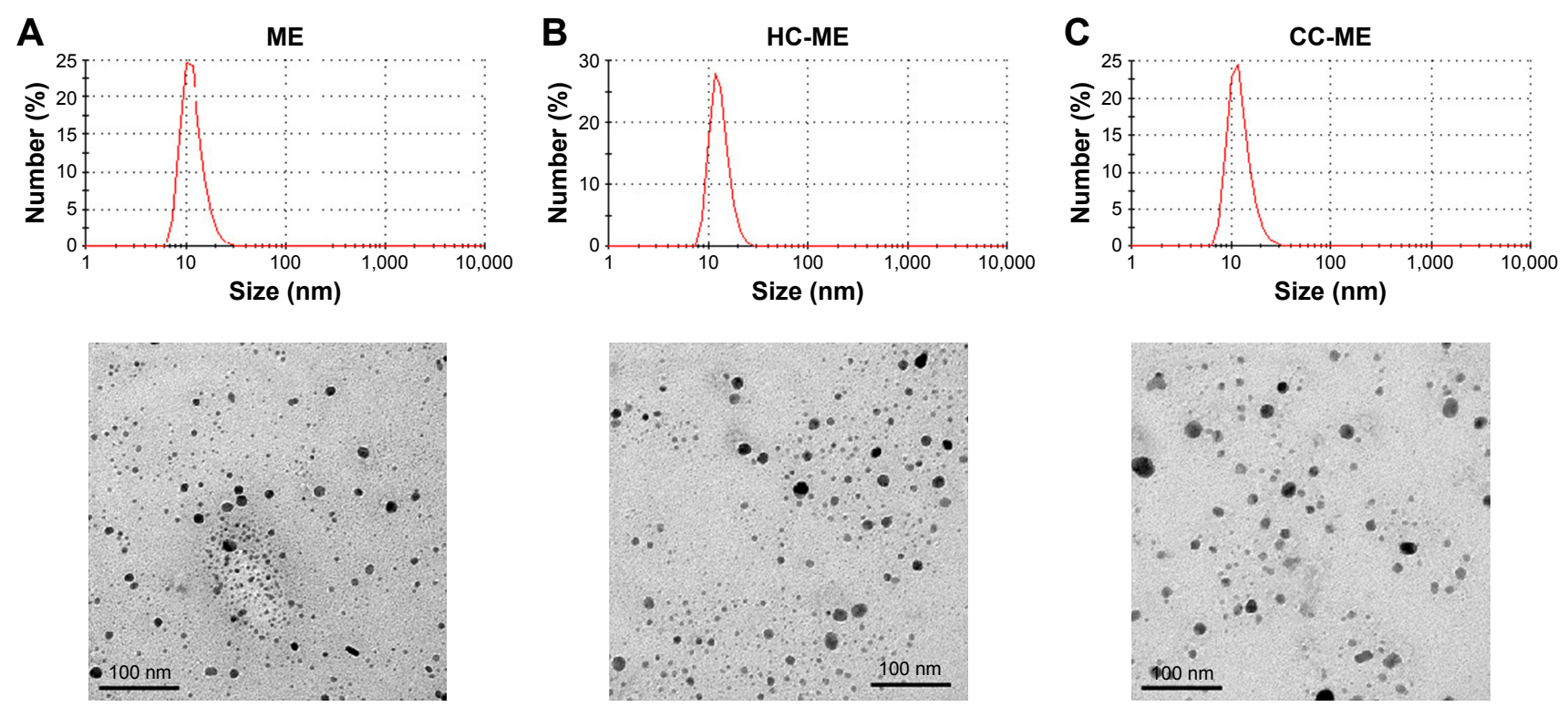

Figure 2 Appearance and micromorphology of ME formulations

Notes: (A) 8-MOP MEs; (B) HC-MEs; (C) CC-MEs. Size distribution assessed by dynamic light scattering; images observed under transmission electron microscopy. Abbreviations: ME, microemulsion; MOP, methoxypsoralen; HC, hydroxypropyl chitosan; CC, carboxymethyl chitosan; PDI, polydispersity index.

\section{Preparation and characterization of chitosan derivative-coated 8-MOP MEs}

Chitosan derivative-coated 8-MOP MEs were prepared using chitosan-derivative solutions $(0.75 \%)$ as the water phase in the selected formulation A. The appearance of the four formulated derivatives - AC-MEs, LC-MEs, CC-MEs, and HC-MEs - was transparent and homogeneous with good fluidity. As summarized in Table 2, all formulations were uniformly distributed (PDI $<0.2$ ), with similar droplet sizes $(17-20 \mathrm{~nm})$. The $\zeta$-potential value also reflects the stability of the formulation, and the absolute $\zeta$-potentials of chitosan derivative-coated MEs were higher than 8-MOP MEs, showing increased stability. $\mathrm{pH}$ values of AC-ME and LC-ME were lower than other formulations, due to the existence of acetate and lactate. The electronic conductivity of AC-ME was higher than other formulations, because of the acetate as a mild acid. However, drug-loading capacity was not significantly different among formulations $\left(1.4-1.7 \mathrm{mg} \mathrm{mL}^{-1}\right)$. Therefore, a balanced amount of drug $\left(1.4 \mathrm{mg} \mathrm{mL}^{-1}\right)$ was chosen for preparing those formulations of equivalent 8-MOP dosage for further experiments. HC-ME and CC-ME particles were also spherical and uniformly distributed in the system (Figure 2B and C).

\section{Comparison of ex vivo skin retention/ permeation of 8-MOP MEs and chitosan derivative-coated 8-MOP MEs}

To compare ex vivo skin permeability of 8-MOP MEs and chitosan derivative-coated MEs, as well as 8-MOP tincture, each formulation was added to abdominal porcine skin at an equivalent dose of 8-MOP. The cumulative permeated amount of 8-MOP $\left(Q_{n}\right)$ is presented in Figure 3A. While less 8-MOP in tincture permeated the skin, it exhibited the lowest retention:permeation ratio (Table 3). 8-MOP MEs showed the highest ex vivo skin permeability, as well as the highest retention:permeation ratio. Retention:permeation ratios of HC-ME and CC-ME were higher than other chitosan-coated 8-MOP ME formulations, and were selected for in vivo pharmacokinetic study (Figure 3B).

Table 2 Physiochemical characterization of 8-MOP MEs and four chitosan derivative-coated 8-MOP MEs

\begin{tabular}{l|l|l|l|l|l|l}
\hline & $\begin{array}{l}\text { Droplet } \\
(\mathbf{n m})\end{array}$ & PDI & $\begin{array}{l}\zeta \text {-potential } \\
(\mathbf{m V})\end{array}$ & $\mathbf{p H}$ & $\begin{array}{l}\text { Conductivity } \\
\left(\mu \mathbf{S} \cdot \mathbf{c m}^{-1}\right)\end{array}$ & $\begin{array}{l}\text { Drug-loading } \\
\mathbf{c a p a c i t y}(\mathbf{m g} \mathbf{m L}\end{array}$ \\
\hline MEs & 17.303 & 0.142 & -17.40 & 6.225 & 24.75 & 1.535 \\
AC-MEs & 18.775 & 0.181 & 25.75 & 4.460 & 69.15 & 1.721 \\
LC-MEs & 17.548 & 0.138 & 37.15 & 4.885 & 37.40 & 1.632 \\
CC-MEs & 19.702 & 0.098 & -20.20 & 7.450 & 29.80 & 1.504 \\
HC-MEs & 20.040 & 0.128 & 28.23 & 6.260 & 32.90 & 1.430 \\
\hline
\end{tabular}

Abbreviations: MOP, methoxypsoralen; MEs, microemulsions; AC, acetic chitosan; LC, lactate chitosan; CC, carboxymethyl chitosan; HC, hydroxypropyl chitosan; PDI, polydispersity index. 
A

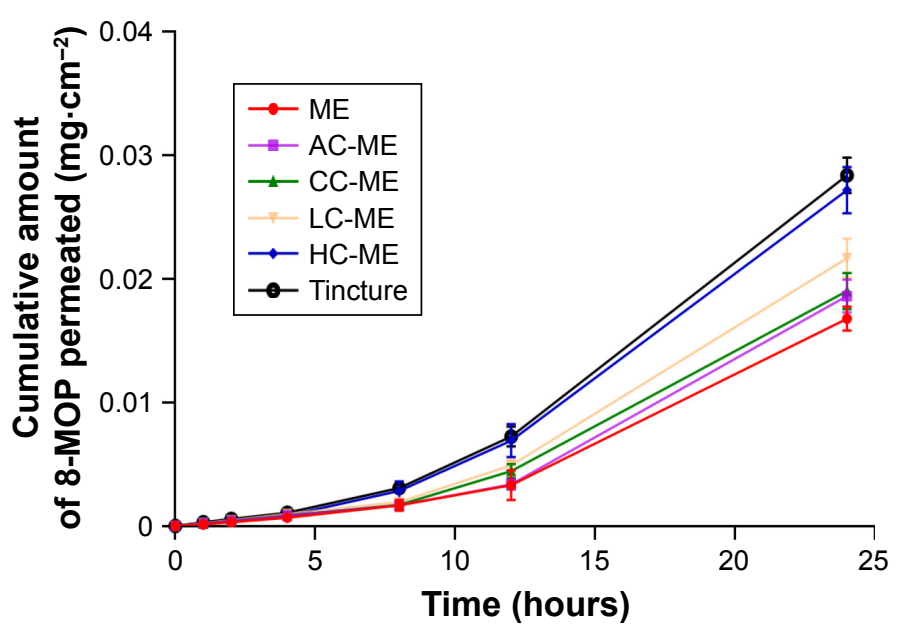

B

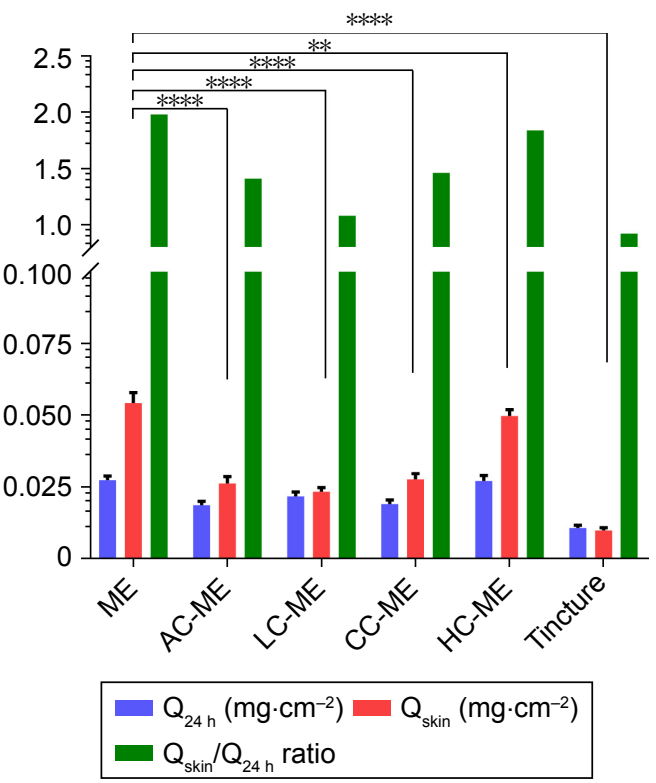

Figure 3 Ex vivo skin-permeation profile of the selected ME formulation, HC-MEs, CC-MEs, AC-MEs, LC-MEs, and tincture ( $n=6$ ).

Notes: (A) Cumulative 12-hour 8-MOP permeation of skin; (B) comparison of 8-MOP retained and permeated in skin and calculated retention:permeation ratio $(* * * * P<0.001, * * P<0.01)$. MEs showed a significantly higher amount of 8-MOP retained in the skin than all chitosan derivative-coated MEs, and also showed the highest ratio of retention:permeation.

Abbreviations: ME, microemulsion; HC, hydroxypropyl chitosan; CC, carboxymethyl chitosan; AC, acetic chitosan; LC, lactate chitosan; MOP, methoxypsoralen.

\section{Pharmacokinetic study}

Figure 4 shows anesthetized rats under pharmacokinetic study. Fur on the abdomen was shaved with no harm to the skin. Microdialysis membrane was steadily implanted in the dermal tissue of the ventral region. UPLC-MS was valid for 8-MOP, internal-standard TMP showed no significant overlap, and chromatography for blank microdialysates and blank plasma showed minimal influence on the sample (Figure S1). Mean in vitro recovery between dialysis (relative recovery $34.4 \% \pm 5.6 \%$ ) and retrodialysis (RL $35.1 \% \pm 3.7 \%$ ) was consistent, with no significant difference between different doses (Figure 5A). Therefore, RL was used for in vivo microdialysis analysis. In vivo recovery was not significantly changed when different concentrations of 8-MOP were

Table 3 Ex vivo skin permeability of 8-MOP MEs, chitosan derivative-coated 8-MOP MEs, and 8-MOP tincture

\begin{tabular}{l|l|l|l}
\hline & $\begin{array}{l}\mathbf{Q}_{24 \text { hours }} \\
\left(\mathbf{m g} \cdot \mathbf{c m}^{-2}\right)\end{array}$ & $\begin{array}{l}\mathbf{Q}_{\text {skin }} \\
\left(\mathbf{m g} \cdot \mathbf{c m}^{-\mathbf{2}}\right)\end{array}$ & $\begin{array}{l}\text { Retention: } \\
\text { permeation }\end{array}$ \\
\hline MEs & $0.02735 \pm 0.00146$ & $0.05431 \pm 0.00364$ & $1.98^{*}$ \\
AC-MEs & $0.01861 \pm 0.00134$ & $0.02617 \pm 0.00238$ & $1.4 I^{*}$ \\
LC-MEs & $0.02169 \pm 0.00156$ & $0.02334 \pm 0.00140$ & 1.08 \\
CC-MEs & $0.01901 \pm 0.00146$ & $0.02766 \pm 0.00202$ & $1.46^{*}$ \\
HC-MEs & $0.02710 \pm 0.00189$ & $0.04976 \pm 0.00221$ & $1.84^{*}$ \\
Tincture & $0.01069 \pm 0.00098$ & $0.00986 \pm 0.00092$ & 0.92 \\
\hline
\end{tabular}

Note: $* P<0.01$ versus tincture.

Abbreviations: MOP, methoxypsoralen; MEs, microemulsion; AC, acetic chitosan; LC, lactate chitosan; CC, carboxymethyl chitosan; HC, hydroxypropyl chitosan. perfused (Figure 5B), and RL for the moderate concentration was relatively low, but generally stable (mean $20.0 \% \pm 1.6 \%$ ) during 12-hour testing (Figure 5C).

Results of in vivo pharmacokinetic study were consistent with the ex vivo study. MEs, HC-MEs, and CC-MEs all showed increased skin retention and decreased plasma 8-MOP concentration than tincture (Figure 6). 8-MOP in tincture was less able to distribute in the skin, but easily permeated the skin and entered the bloodstream. 8-MOP in CC-MEs released and distributed in the skin very quickly, but were not retained. 8-MOP in HC-MEs was released in controlled fashion and was steadily distributed in the skin, but also a higher amount of 8-MOP permeated the skin and entered the bloodstream than CC-MEs. However, 8-MOP MEs were readily distributed and retained in the skin, and the amount of 8-MOP permeating the skin significantly decreased. Quantitatively, ME was the only formulation with dialysate $\mathrm{AUC}_{0-12 \text { hours }}$ higher than plasma $\mathrm{AUC}_{0-12 \text { hours }}$ (Tables 4 and 5). MEs showed better skin-retention ability (3.05-fold higher than tincture, 1.63-fold higher than CC-MEs, and 1.34-fold higher than HC-MEs). More importantly, plasma $\mathrm{AUC}_{0-12 \text { hours }}$ for 8-MOP MEs was significantly decreased (0.54-fold less than tincture, 0.66 fold less than CC-ME and 0.59-fold less than HC-ME). Therefore, the skin-targeting ability of ME was better than HC-MEs and CC-MEs, with a substantially increased ratio of $\mathrm{AUC}_{\text {dialysate }}: \mathrm{AUC}_{\text {plasma }}$. 

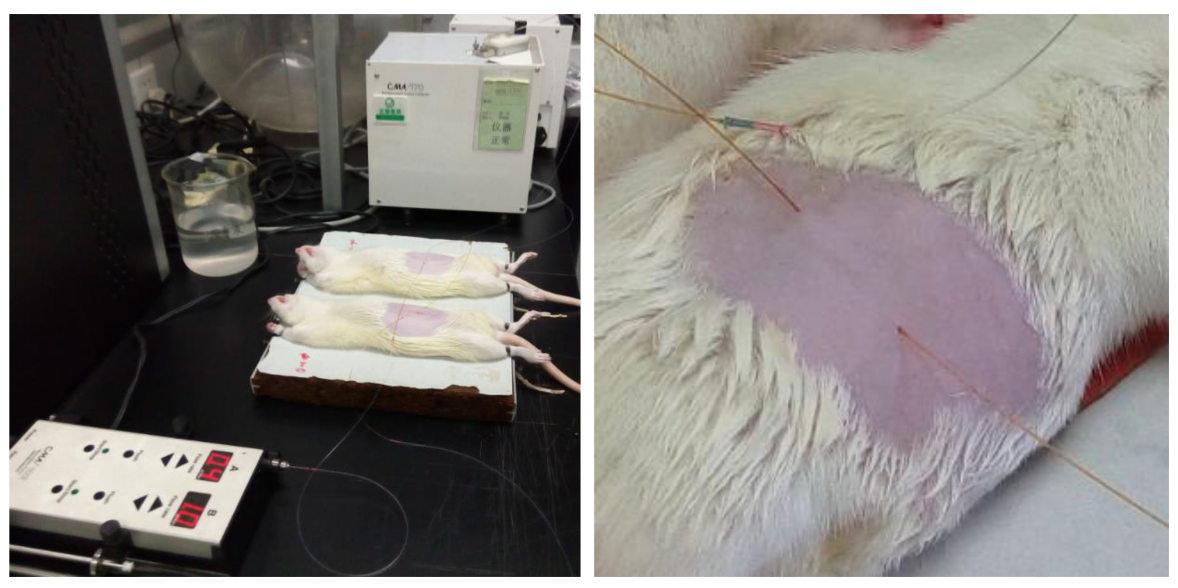

Figure 4 Rats under in vivo pharmacokinetic study.
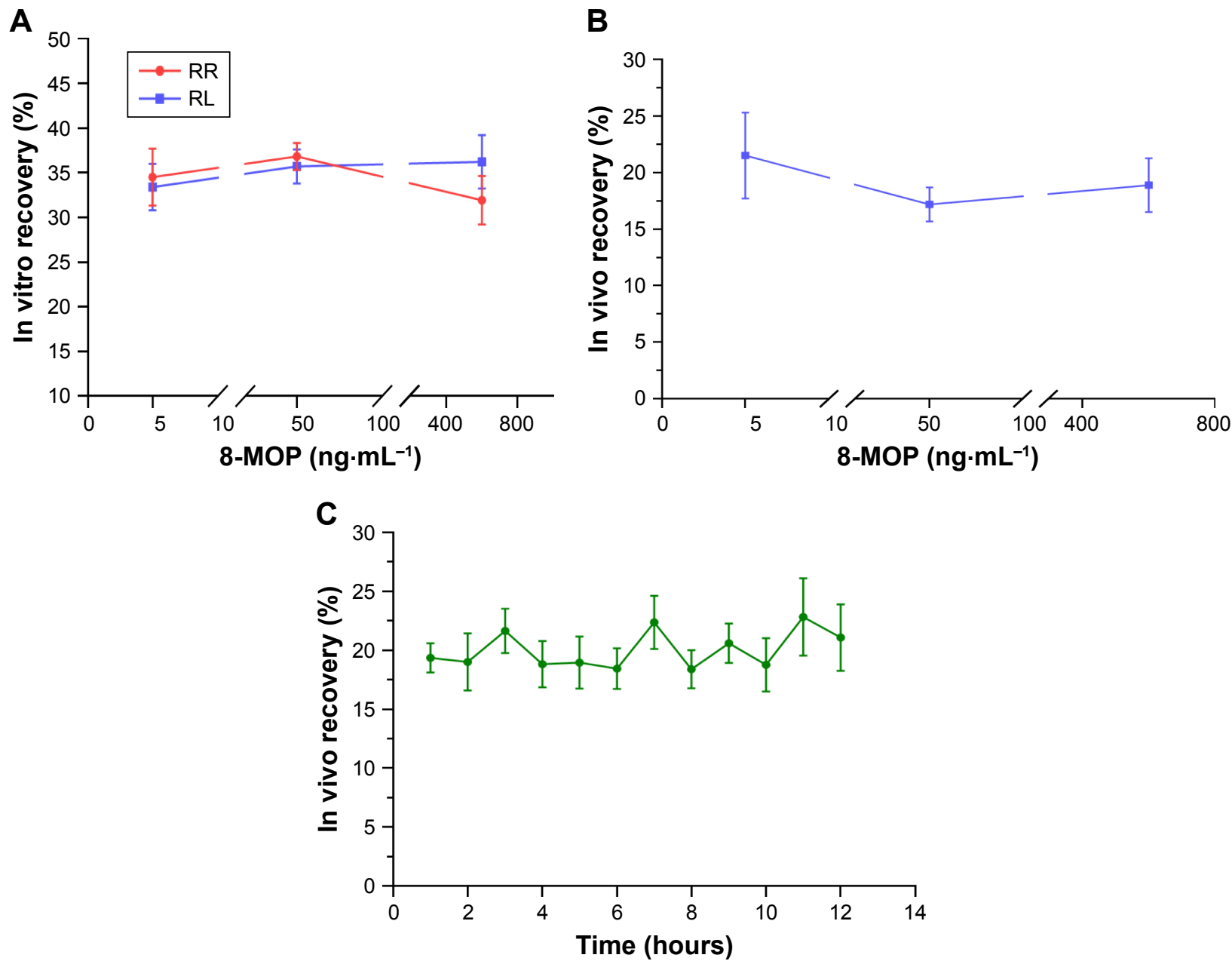

Figure 5 In vitro and in vivo recovery from microdialysis $(n=5)$.

Notes: RR was obtained by the incremental method and RL by the decremental method. (A) In vitro RR and RL for different concentrations of $8-M O P$ (5, 50 , and 600 $\mathrm{ng} \mathrm{mL} \mathrm{L}^{-1}$ ) perfused. RR and RL showed no significant difference, and RL was used as an alternative for RR. (B) In vivo recovery (RL) for different concentrations of 8-MOP $\left(5,50\right.$, and $\left.600 \mathrm{ng} \mathrm{mL}^{-1}\right)$. In vivo recovery was consistent for different concentrations of 8-MOP. (C) Stability of in vivo recovery during I2-hour testing, when a moderate concentration of 8-MOP $\left(50 \mathrm{ng} \mathrm{mL}^{-1}\right)$ was perfused. In vivo recovery over 12 hours was generally stable for analysis.

Abbreviations: MOP, methoxypsoralen; RR, relative recovery; RL, relative loss. 

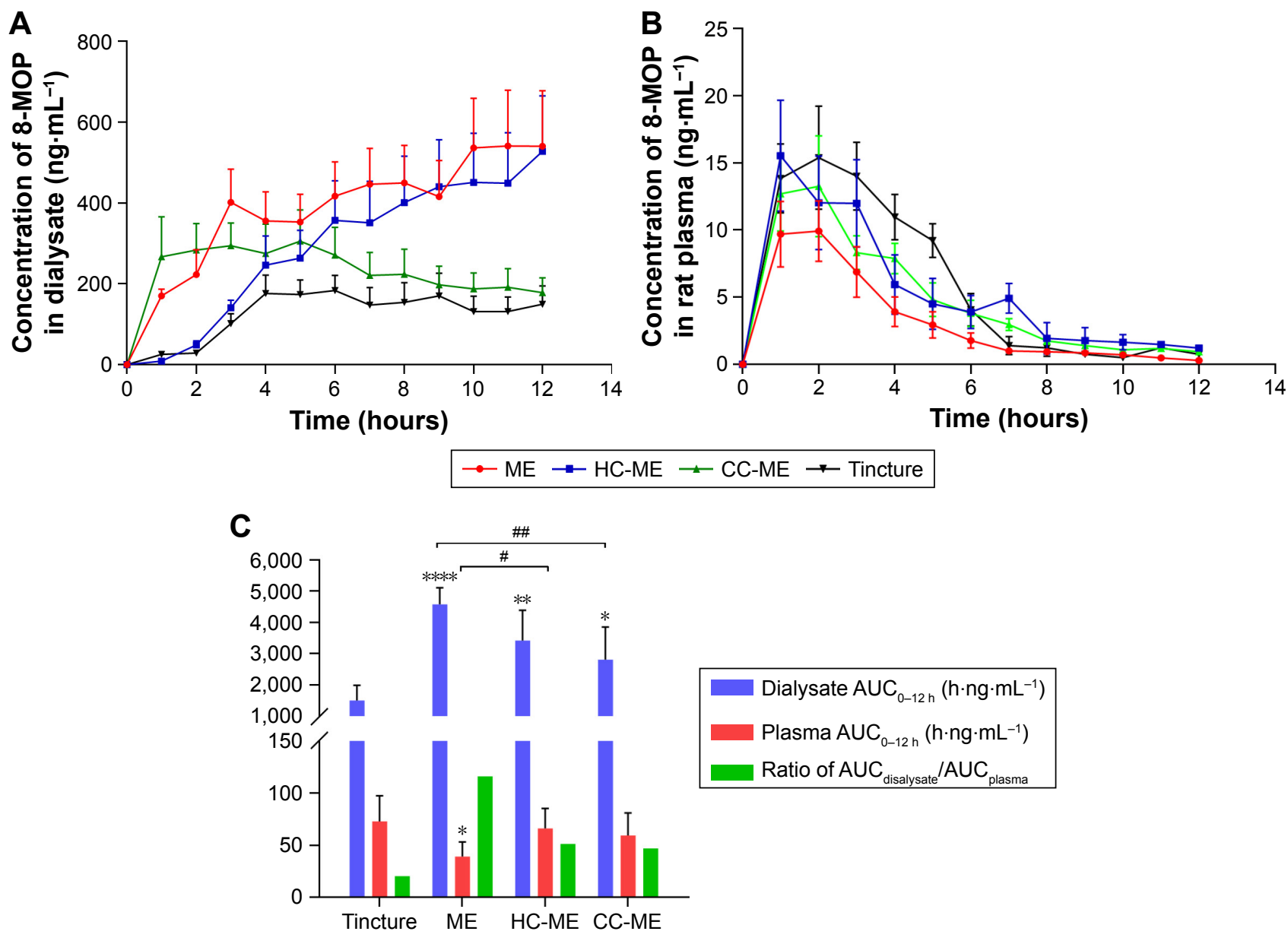

Figure 6 In vivo pharmacokinetic profile of 8-MOP MEs, HC-MEs, CC-MEs, and tincture ( $n=6)$.

Notes: (A) Dermal concentration-time profiles over 12 hours of 8-MOP retained in the skin; (B) 12-hour plasma concentration-time profiles of 8-MOP; (C) comparison of 8-MOP retained $\left(A \cup C_{\text {dialysate }}\right)$ and permeated $\left(A \cup C_{\text {plasma }}\right.$ ) in skin and calculated retention:permeation ratio (compared to tincture, $* * * * P<0.00 \mathrm{I}, * * P<0.0 \mathrm{I}, * P<0.05$; compared to MEs, ${ }^{\# P}<0.01$, $\left.{ }^{\#} P<0.05\right)$. MEs showed a significantly higher amount of 8-MOP retained in the skin than any other formulation, as well as the highest ratio of $\mathrm{AUC}_{\text {dialysate }}: \mathrm{AUC}_{\text {plasma: }}$.

Abbreviations: MOP, methoxypsoralen; MEs, microemulsions; HC, hydroxypropyl chitosan; CC, carboxymethyl chitosan.

\section{Discussion}

In this study, we aimed to enhance the retention of 8-MOP in the skin while reducing its entry to the bloodstream (skin permeation) using MEs and chitosan derivative-coated MEs as delivery vehicles. Of various 8-MOP formulations prepared, we selected three formulations, MEs, HC-MEs,

Table 4 Pharmacokinetic parameters of microdialysate samples

\begin{tabular}{l|l|l|l}
\hline & $\begin{array}{l}\boldsymbol{t}_{\max } \\
\text { (hours) }\end{array}$ & $\begin{array}{l}\mathbf{C}_{\max } \\
\left(\mathbf{n g} \cdot \mathbf{m L}^{-1}\right)\end{array}$ & $\begin{array}{l}\mathbf{A U C}_{\mathbf{0 - 1 2} \text { hours }} \\
\left(\mathbf{h} \cdot \mathbf{n g} \cdot \mathbf{m L}^{-1}\right)\end{array}$ \\
\hline Tincture & 6 & $183.40 \pm 48.55$ & $\mathrm{I}, 500.16 \pm 487.22$ \\
MEs & $\mathrm{II}$ & $540.82 \pm 138.29 *$ & $4,578.56 \pm 537.10^{*}$ \\
HC-MEs & 12 & $527.38 \pm 137.73^{*}$ & $3,422.47 \pm 973.85^{*}$ \\
CC-MEs & 5 & $305.79 \pm 77.44^{*}$ & $2,808.5 \mathrm{I} \pm 1,038.83^{*}$ \\
\hline
\end{tabular}

Note: $* P<0.05$ versus tincture.

Abbreviations: MEs, microemulsions; HC, hydroxypropyl chitosan; CC, carboxymethyl chitosan; $C_{\text {max }}$ maximum concentration; $t_{\text {max }}$, time to $C_{\max }$. and CC-ME, as vehicles for topical delivery of 8-MOP. While the ME formulation exhibited enhanced skin-targeting effects of 8-MOP, chitosan derivatives failed to enhance the skin-targeting effects of 8-MOP MEs further. Nevertheless, the selected 8-MOP ME formulation was a simple and promising vehicle for targeted skin delivery of 8-MOP.

Table 5 Pharmacokinetic parameters of plasma samples

\begin{tabular}{|c|c|c|c|}
\hline & $\begin{array}{l}t_{\max } \\
\text { (hours) }\end{array}$ & $\begin{array}{l}C_{\max } \\
\left(\mathbf{n g} \cdot \mathrm{mL}^{-1}\right)\end{array}$ & $\begin{array}{l}\text { AUC }_{0-12 \text { hours }} \\
\left.\text { (h.ng } \cdot \mathrm{mL}^{-1}\right)\end{array}$ \\
\hline Tincture & 2 & $15.38 \pm 3.84$ & $73.02 \pm 24.58$ \\
\hline MEs & 2 & $9.93 \pm 2.25^{*}$ & $39.35 \pm 13.90 *$ \\
\hline HC-MEs & I & $15.53 \pm 4.12$ & $66.32 \pm 19.33$ \\
\hline CC-MEs & 2 & $13.25 \pm 3.75$ & $59.70 \pm 21.50$ \\
\hline
\end{tabular}

Note: $* P<0.05$ versus tincture.

Abbreviations: MEs, microemulsions; HC, hydroxypropyl chitosan; CC, carboxymethyl chitosan; $C_{\max }$, maximum concentration; $t_{\max }$, time to $C_{\max }$. 
In our preparation of $\mathrm{ME}$ formulations, we did not assign much priority to drug loading. Drug retention in the skin is dependent on drug distribution between the vehicle and the skin. ${ }^{25} \mathrm{ME}$ formulations with elevated adherence and spreadability on the skin, as well as permeation ability through the stratum corneum, would be more likely to reduce skin-layer partitioning and prolong retention of the drug in the skin. ${ }^{26,27}$ Therefore, ME formulations were firstly selected for their stability and solubility for preparing oil-in-water MEs of 8-MOP and then selected for their skin-targeting ability. Of ME formulations of various compositions prepared, only three were homogeneous, clear, and transparent after the stability test and suitable for drug-loading.

In our ex vivo skin retention/permeation study, formulation A showed the highest skin retention:permeation ratio and was selected for in vivo study. Surfactants and cosurfactants may interact with skin components and reversibly weaken its barrier capability and facilitate drug permeation. ${ }^{28}$ The $\mathrm{Q}_{24}$ and $\mathrm{Q}_{\text {skin }}$ of formulations $\mathrm{A}$ and $\mathrm{C}$ were higher than formulation $\mathrm{B}$, because ethanol can enhance skin permeation. ${ }^{29,30}$ Formulation $\mathrm{C}$ contained oleic acid, and showed improved transdermal ability. ${ }^{31,32}$ Therefore, formulation A was able to penetrate the stratum corneum, but less able to permeate the skin, and showed the highest retention:permeation ratio. In our following ex vivo skin-permeation study comparing the $\mathrm{ME}$ (formulation A) and chitosan-coated MEs, HC-MEs, and $\mathrm{CC}-\mathrm{MEs}$ showed higher retention:permeation ratio than AC-MEs and LC-MEs. This could be attributed to the low $\mathrm{pH}$ values of $\mathrm{AC}$ and $\mathrm{LC}$, as the composition of the ME formulation was consistent among all formulations. It has been reported that high $\mathrm{pH}$ values of formulations can quickly increase skin $\mathrm{pH}$ and alter stratum corneum integrity/ cohesion alterations, leading to increased permeability. ${ }^{33}$

In our pharmacokinetic study, the concentration of 8-MOP retained in the skin increased cumulatively, but the 8-MOP plasma time-concentration curve looked like single-dose oral administration (Figure 6B). We speculate that the majority of penetration enhancers, like water, oil, and surfactants/ cosurfactants in the formulations were quickly ( $<2$ hours) absorbed and dissipated in the skin during the skin-permeation process, leaving 8-MOP retained in the skin with less entering the bloodstream. For drug retained in the skin, elimination was slow and the amount appeared to be accumulating during 12-hour microdialysis. Increased skin permeation of HC-MEs and CC-MEs over MEs confirmed that chitosan derivatives can help permeate the dermis layer. Also, skin retention for HC-MEs was slightly higher than CC-MEs, and this could be attributed to the positive $\zeta$-potential of HC-MEs, which interacted with tight-junction proteins in the skin. ${ }^{34-36}$ However, further studies concerning the skin-permeation mechanism for chitosan-coated ME are warranted.

In conclusion, three selected formulations (8-MOP MEs, HC-MEs, and CC-MEs) successfully enhanced skin retention and decreased skin permeation of 8-MOP. However, neither HC-MEs nor CC-MEs further increased the skin-targeting effects of 8-MOP over MEs. Superior skin-targeting effects of MEs were highlighted, and the 8-MOP ME formulation containing $2.9 \%$ ethyl oleate, $17.2 \%$ EL35, $8.6 \%$ ethanol and $71.3 \%$ water could be a promising and safe alternative for the treatment of vitiligo.

\section{Acknowledgment}

This work was supported by the Hunan Provincial Science and Technology Plan (2016TP2002), Nature Science Foundation of China (NSFC81573718), and Hunan Provincial Natural Science Foundation of China (2019JJ50882).

\section{Disclosure}

The authors report no conflicts of interest in this work.

\section{References}

1. Frisoli ML, Harris JE. Vitiligo: mechanistic insights lead to novel treatments. J Allergy Clin Immun. 2017;140:654-662. doi:10.1016/j. jaci.2017.07.011

2. Ezzedine $\mathrm{K}$, Sheth V, Rodrigues M, et al. Vitiligo is not a cosmetic disease. J Am Acad Dermatol. 2015;73:883-885. doi:10.1016/j.jaad. 2015.07.039

3. Rashighi M, Harris JE. Vitiligo pathogenesis and emerging treatments. Dermatol Clin. 2017;35:257-265. doi:10.1016/j.det.2016.11.014

4. Rodrigues M, Ezzedine K, Hamzavi I, Pandya AG, Harris JE; Vitiligo Working Group. New discoveries in the pathogenesis and classification of vitiligo. J Am Acad Dermatol. 2017;77:1-13. doi:10.1016/j.jaad. 2016.10.048

5. Homan MWL, Spuls PI, de Korte J, Bos JD, Sprangers MA, van der Veen JPW. The burden of vitiligo: patient characteristics associated with quality of life. J Am Acad Dermatol. 2009;61:411-420. doi:10.1016/j. jaad.2009.03.022

6. Rodrigues M, Ezzedine K, Hamzavi I, Pandya AG, Harris JE; Vitiligo Working Group. Current and emerging treatments for vitiligo. $J \mathrm{Am}$ Acad Dermatol. 2017;77:17-29. doi:10.1016/j.jaad.2016.11.010

7. Taieb A, Alomar A, Boehm M, et al; Vitiligo European Task Force (VETF); European Academy of Dermatology and Venereology (EADV); Union Européenne des Médecins Spécialistes (UEMS). Guidelines for the management of vitiligo: the European Dermatology Forum consensus. Br J Dermatol. 2013;168:5-19. doi:10.1111/j.1365-2133.2012.11197.x

8. Yones SS, Palmer RA, Garibaldinos TM, Hawk JLM. Randomized double-blind trial of treatment of vitiligo - efficacy of psoralen-UV-A therapy vs narrowband-LTV-B therapy. Arch Dermatol. 2007;143: 578-584. doi:10.1001/archderm.143.5.578

9. Lapolla W, Yentzer BA, Bagel J, Halvorson CR, Feldman SR. A review of phototherapy protocols for psoriasis treatment. $J$ Am Acad Dermatol. 2011;64:936-949. doi:10.1016/j.jaad.2009.12.054

10. Ozkan I, Kose O, Ozmen I, Arca E. Efficacy and safety of non-laser, targeted UVB phototherapy alone and in combination with psoralen gel or calcipotriol ointment in the treatment of localized, chronic, plaque-type psoriasis. Int J Dermatol. 2012;51:609-613. doi:10.1111/j. 1365-4632.2011.05257.x 
11. Horio T, Okamoto H. The mechanisms of inhibitory effect of 8-methoxypsoralen and long-wave ultraviolet light on experimental contact sensitization. J Invest Dermatol. 1982;78:402-405.

12. Grundmann-Kollmann M, Tegeder I, Ochsendorf FR, et al. Kinetics and dose-response of photosensitivity in cream psoralen plus ultraviolet A photochemotherapy: comparative in vivo studies after topical application of three standard preparations. Br J Dermatol. 2001;144:991-995. doi:10.1046/j.1365-2133.2001.04187.x

13. Mizuno N, Enami H, Esaki K. Effect of 8-methoxypsoralen plus UVA on psoriasis leukotactic factor. J Invest Dermatol. 1979;72:64-66.

14. Wolff K. Side-effects of psoralen photochemotherapy (PUVA). Br J Dermatol. 1990;122(Suppl 36):117-125.

15. Garg BJ, Garg NK, Beg S, Singh B, Katare OP. Nanosized ethosomesbased hydrogel formulations of methoxsalen for enhanced topical delivery against vitiligo: formulation optimization, in vitro evaluation and preclinical assessment. J Drug Target. 2016;24:233-246. doi:10.3109/ 1061186X.2015.1070855

16. Wu C-S, Lan -C-CE, Wang L-F, Chen G-S, Wu C-S, Yu H-S. Effects of psoralen plus ultraviolet A irradiation on cultured epidermal cells in vitro and patients with vitiligo in vivo. Br J Dermatol. 2007;156: 122-129. doi:10.1111/j.1365-2133.2006.07584.x

17. Borowska K, Wolowiec S, Rubaj A, Glowniak K, Sieniawska E, Radej S. Effect of polyamidoamine dendrimer G3 and G4 on skin permeation of 8-methoxypsoralene-in vivo study. Int J Pharmaceut. 2012;426: 280-283. doi:10.1016/j.ijpharm.2012.01.041

18. Fanun M. Microemulsions as delivery systems. Curr Opin Colloid In. 2012;17:306-313. doi:10.1016/j.cocis.2012.06.001

19. Chen HB, Chang XL, Weng T, et al. A study of microemulsion systems for transdermal delivery of triptolide. J Control Release. 2004;98: 427-436. doi:10.1016/j.jconrel.2004.06.001

20. Shen LN, Zhang YT, Wang Q, Xu L, Feng NP. Preparation and evaluation of microemulsion-based transdermal delivery of total flavone of rhizoma arisaematis. Int J Nanomed. 2014;9:3453-3464.

21. Kreilgaard M. Influence of microemulsions on cutaneous drug delivery. Adv Drug Deliver Rev. 2002;54:S77-S98. doi:10.1016/S0169409X(02)00116-3

22. Kumari B, Kesavan K. Effect of chitosan coating on microemulsion for effective dermal clotrimazole delivery. Pharm Dev Technol. 2017; 22:617-626. doi:10.1080/10837450.2016.1230629

23. Voelkner NMF, Voelkner A, Costa J, et al. Dermal pharmacokinetics of pyrazinamide determined by microdialysis sampling in rats. Int $J$ Antimicrob Ag. 2018;51:190-196. doi:10.1016/j.ijantimicag.2017. 10.001

24. Kreilgaard M. Dermal pharmacokinetics of microemulsion formulations determined by in vivo microdialysis. Pharmaceut Res. 2001;18: 367-373. doi:10.1023/A:1011067300397
25. Prow TW, Grice JE, Lin LL, et al. Nanoparticles and microparticles for skin drug delivery. Adv Drug Deliver Rev. 2011;63:470-491. doi:10.1016/j.addr.2011.01.012

26. Rai VK, Mishra N, Yadav KS, Yadav NP. Nanoemulsion as pharmaceutical carrier for dermal and transdermal drug delivery: formulation development, stability issues, basic considerations and applications. JControl Release. 2018;270:203-225. doi:10.1016/j.jconrel.2017.11.049

27. Matougui N, Boge L, Groo A-C, et al. Lipid-based nanoformulations for peptide delivery. Int J Pharmaceut. 2016;502:80-97. doi:10.1016/j. ijpharm.2016.02.019

28. Nastiti CM, Ponto T, Abd E, Grice JE, Benson HAE, Roberts MS. Topical nano and microemulsions for skin delivery. Pharmaceutics. 2017;9:37. doi:10.3390/pharmaceutics9040037

29. Lopes LB, Garcia MT, Bentley MV. Chemical penetration enhancers Ther Deliv. 2015;6:1053-1061. doi:10.4155/tde.15.61

30. Williams AC, Barry BW. Penetration enhancers. Adv Drug Deliv Rev. 2004;56:603-618. doi:10.1016/j.addr.2003.10.025

31. Dubey V, Mishra D, Nahar M, Jain NK. Vesicles as tools for the modulation of skin permeability. Expert Opin Drug Del. 2007;4:579-593. doi:10.1517/17425247.4.6.579

32. Larrucea E, Arellano A, Santoyo S, Ygartua P. Combined effect of oleic acid and propylene glycol on the percutaneous penetration of tenoxicam and its retention in the skin. Eur J Pharm Biopharm. 2001;52: 113-119.

33. Hachem JP, Man MQ, Crumrine D, et al. Sustained serine proteases activity by prolonged increase in $\mathrm{pH}$ leads to degradation of lipid processing enzymes and profound alterations of barrier function and stratum corneum integrity. J Invest Dermatol. 2005;125:510-520. doi:10.1111/j.0022-202X.2005.23838.x

34. Turner JR, Buschmann MM, Romero-Calvo I, Sailer A, Shen L. The role of molecular remodeling in differential regulation of tight junction permeability. Semin Cell Dev Biol. 2014;36:204-212. doi:10.1016/j. semcdb.2014.09.022

35. Brandner JM. Tight junctions and tight junction proteins in mammalian epidermis. Eur J Pharm Biopharm. 2009;72:289-294. doi:10.1016/j. ejpb.2008.08.007

36. Yoshida K, Yokouchi M, Nagao K, Ishii K, Amagai M, Kubo A. Functional tight junction barrier localizes in the second layer of the stratum granulosum of human epidermis. J Dermatol Sci. 2013;71:89-99. doi:10.1016/j.jdermsci.2013.04.021 


\section{Supplementary materials}

Table SI Details of three 8-MOP ME formulations

\begin{tabular}{l|l|l|l|l}
\hline & Oil phase (w:w) & Surfactant (w:w) & Cosurfactant (w:w) & Water phase (w:w) \\
\hline A & Ethyl oleate (2.9\%) & EL35 (17.2\%) & Ethanol (8.6\%) & Water (7I.3\%) \\
B & Ethyl oleate (2.7\%) & Solutol (16.2\%) & Propylene glycol (8.1\%) & Water (73.0\%) \\
C & Oleic acid (2.7\%) & RH40 (16.3\%) & Ethanol (8.1\%) & Water (72.9\%) \\
\hline
\end{tabular}

Abbreviations: MOP, methoxypsoralen; MEs, microemulsion.

Table S2 Preliminary stability of 8-MOP MEs, CC-MEs, and HC-MEs

\begin{tabular}{|c|c|c|c|c|c|c|c|}
\hline & ${ }^{\circ} \mathbf{C}$ & $\begin{array}{l}\text { Time } \\
\text { (day) }\end{array}$ & $\begin{array}{l}\text { Mean size } \\
(\mathrm{nm})\end{array}$ & PDI & $\begin{array}{l}\zeta \text {-potential } \\
(\mathrm{mV})\end{array}$ & $\mathrm{pH}$ & $\begin{array}{l}\text { Conductivity } \\
\left(\mu \mathbf{S} \cdot \mathbf{c m}^{-1}\right)\end{array}$ \\
\hline \multirow[t]{4}{*}{ MEs } & \multirow[t]{2}{*}{4} & 30 & $17.95 \pm 0.76$ & $0.11 \pm 0.03$ & $-18.67 \pm 1.78$ & $6.23 \pm 0.23$ & $23.52 \pm 1.98$ \\
\hline & & 60 & $18.85 \pm 0.66$ & $0.16 \pm 0.06$ & $-19.21 \pm 1.67$ & $6.45 \pm 0.31$ & $26.73 \pm 1.12$ \\
\hline & \multirow[t]{2}{*}{25} & 30 & $18.02 \pm 0.43$ & $0.10 \pm 0.01$ & $-|7.83 \pm 2.5|$ & $6.60 \pm 0.11$ & $27.3 \mathrm{I} \pm \mathrm{I} .40$ \\
\hline & & 60 & $19.09 \pm 1.33$ & $0.18 \pm 0.07$ & $-15.30 \pm 1.10$ & $6.73 \pm 0.51$ & $24.7 I \pm 2.44$ \\
\hline \multirow[t]{4}{*}{ CC-MEs } & \multirow[t]{2}{*}{4} & 30 & $19.65 \pm 0.42$ & $0.19 \pm 0.08$ & $-21.42 \pm 1.35$ & $7.12 \pm 0.45$ & $31.25 \pm 0.65$ \\
\hline & & 60 & $19.87 \pm 0.68$ & $0.21 \pm 0.03$ & $-23.52 \pm 1.82$ & $7.32 \pm 0.67$ & $30.12 \pm 0.49$ \\
\hline & \multirow[t]{2}{*}{25} & 30 & $19.95 \pm 0.19$ & $0.09 \pm 0.01$ & $-24.6 I \pm I .7 \mid$ & $7.45 \pm 0.43$ & $33.07 \pm 0.22$ \\
\hline & & 60 & $20.12 \pm 0.77$ & $0.12 \pm 0.02$ & $-26.32 \pm 1.55$ & $7.62 \pm 0.22$ & $29.55 \pm 1.17$ \\
\hline \multirow[t]{4}{*}{ HC-MEs } & \multirow[t]{2}{*}{4} & 30 & $20.14 \pm 0.86$ & $0.17 \pm 0.02$ & $26.47 \pm 1.42$ & $6.36 \pm 0.56$ & $30.31 \pm 1.09$ \\
\hline & & 60 & $20.2 I \pm 0.56$ & $0.23 \pm 0.05$ & $27.82 \pm 1.13$ & $6.11 \pm 0.60$ & $34.09 \pm 1.21$ \\
\hline & \multirow[t]{2}{*}{25} & 30 & $20.16 \pm 1.06$ & $0.19 \pm 0.06$ & $28.74 \pm I .8 \mid$ & $6.52 \pm 0.12$ & $32.06 \pm 1.73$ \\
\hline & & 60 & $21.84 \pm 0.79$ & $0.13 \pm 0.03$ & $29.91 \pm 2.12$ & $6.48 \pm 0.35$ & $36.32 \pm 1.05$ \\
\hline
\end{tabular}

Abbreviations: MOP, methoxypsoralen; MEs, microemulsions; CC, carboxymethyl chitosan; HC, hydroxypropyl chitosan; PDI, polydispersity index. 

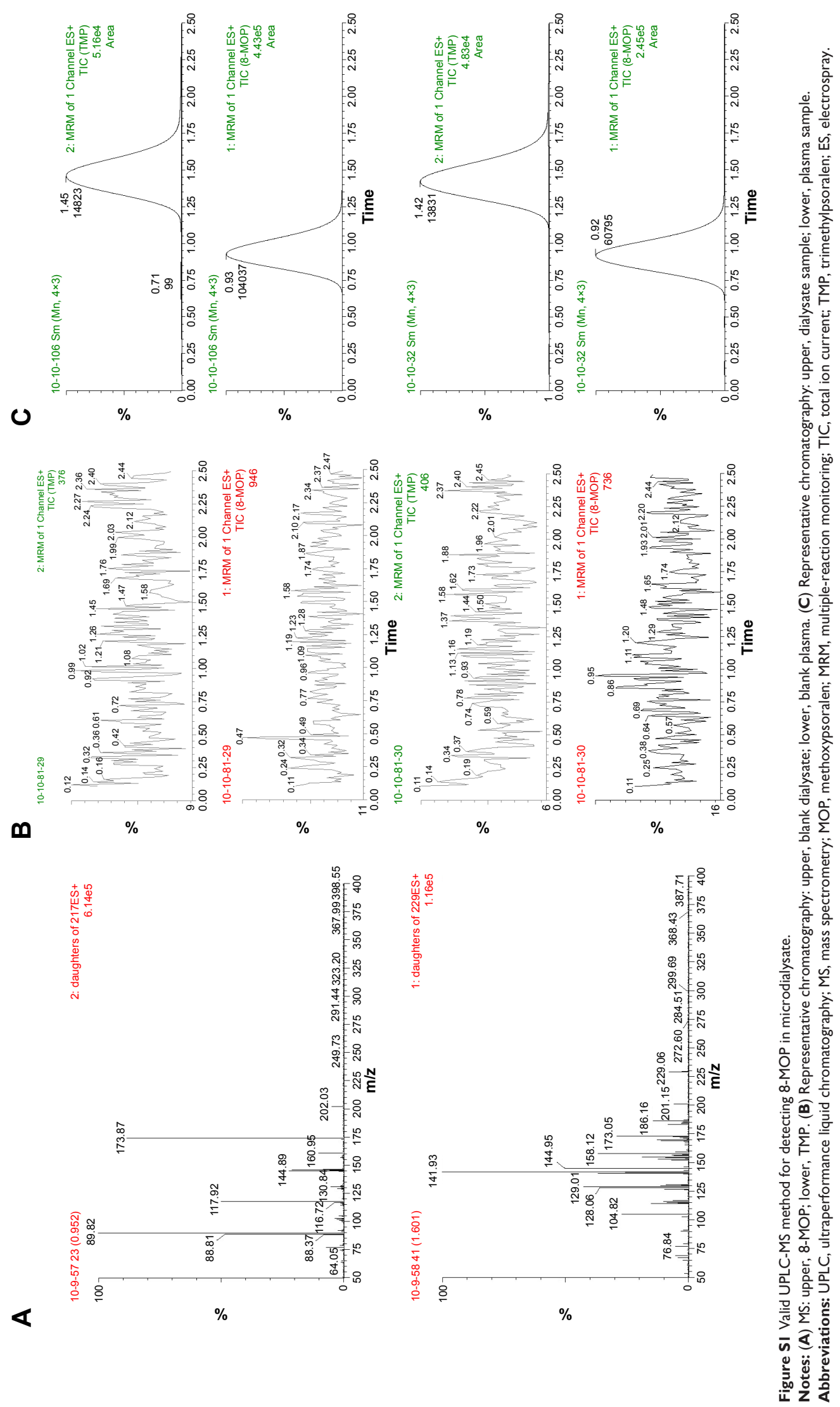


\section{Publish your work in this journal}

The International Journal of Nanomedicine is an international, peerreviewed journal focusing on the application of nanotechnology in diagnostics, therapeutics, and drug delivery systems throughout the biomedical field. This journal is indexed on PubMed Central,

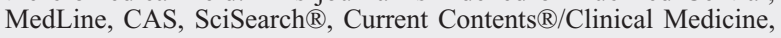

Journal Citation Reports/Science Edition, EMBase, Scopus and the Elsevier Bibliographic databases. The manuscript management system is completely online and includes a very quick and fair peer-review system, which is all easy to use. Visit http://www.dovepress.com/ testimonials.php to read real quotes from published authors.

Submit your manuscript here: http://www.dovepress.com/international-journal-of-nanomedicine-journal 